NBER WORKING PAPER SERIES

\title{
ANTI-COMPETITIVE AND RENT-SHIFTING \\ ASPECTS OF DOMESTIC-CONTENT \\ PROVISIONS IN REGIONAL TRADE BLOCKS
}

\author{
Florencio Lopez-de-Silanes \\ James R. Markusen \\ Thomas F. Rutherford
}

Working Paper No. 4512

\section{NATIONAL BUREAU OF ECONOMIC RESEARCH 1050 Massachusetts Avenue \\ Cambridge, MA 02138 \\ October, 1993}

The first draft of this paper was prepared while Markusen was a visitor at the LSE during June of 1993. He thanks Tony Venables and other members of the LSE for their hospitality and helpful discussions. Markusen's portion of this research was funded by NSF grant SES9022898. This paper is part of NBER's research program in International Trade and Investment. Any opinions expressed are those of the authors and not those of the National Bureau of Economic Research. 
NBER Working Paper \#4512

October 1993

\title{
ANTI-COMPETTIIVE AND RENT-SHIFTING \\ ASPECTS OF DOMESTIC-CONTENT \\ PROVISIONS IN REGIONAL TRADE BLOCKS
}

\begin{abstract}
Regional trade agreements must specify domestic-content rules (rules of origin) that define the conditions under which a good qualifies as "domestic" and so may be freely traded within the block. The paper analyzes such rules, focussing in particular on oligopolistic industries in which foreign multinationals producing within the block rely much more on imported intermediate inputs than do domestic furms. In such a situation, we argue that domestic content provisions are anti-competitive, reducing overall final output of the industry, and shift rents (in the absence of free entry) to domestic firms. It is possible that the anti-competitive aspect of the rules are sufficiently strong that total industry profits rise and the equilibrium demand for the substitute domestic inputs falls (the scale effect of reduced output outweighs a substitution effect in favor of domestic intermediates). The latter effect is more likely to the extent that the foreign multinationals can switch from producing within the block to exporting to the block. These ideas are then examined numerically using an applied general-equilibrium model of the North American auto industry.
\end{abstract}

Florencio Lopez-de-Silanes

National Bureau of Economics 1050 Massachusetts Avenue

Cambridge, MA 02138

Thomas F. Rutherford

Department of Economics

University of Colorado

Boulder, CO 80309-0256
James R. Markusen

Department of Economics University of Colorado Boulder, CO 80309-0256 and NBER 
Regional trade blocks by nature need rules concerning whether or not a product is "domestic" in the sense that it qualifies for free trade within the block. The Canada-US free-trade area has such rules, and the proposed North-American free-trade area elaborates content provisions in great detail. The EEC must similarly devote much attention to defining European products according to content. Domestic-content provisions (or rules of origin) have proved difficult negotiating points in new free-trade agreements (or in the modification of existing agreements) and/or have caused tension between (proposed) member countries and non-members. In the latter vein, a group of firms within the proposed block (often concentrated in one or a few countries) fears that the creation of a large free-trade area will induce foreign firms to produce within the block, thereby increasing competition and lowering profits for the indigenous firms. Insofar as foreign producers are "tooled" to use substantial amounts of imported intermediate inputs, one way of discouraging foreign entry or at least raising the rivals' cost is through a tough domestic content provision for those firms. Rules of origin seem to have been used in this "anti-competitive" manner in the case of the European VCR industry and the North American auto industry.

An example of the type of conflict that domestic-content provisions can generate among member countries occurs when intermediate goods producers (auto parts, semiconductors, textiles) might be concentrated in country A while the final goods producers (auto assembly, computers, clothing) might be concentrated in country $\mathrm{B}$, the latter using substantial amounts of imported components. The government of A (representing the intermediate goods producers $n$ A) wants a high domestic-content ratio as a quid-pro-qui for (trade diverting) imports of the final goods from $B$. Thus the Americans wanted a high North American content ratio in clothing (the "yarn 
forward" rule) so that job losses due to clothing imported from Mexico would be compensated for by increased US fiber, yarn, and textile exports to Mexico.

The purpose of this paper is to consider certain theoretical aspects of domestic-content provisions, and then examine their effects in the specific context of the proposed North American Free Trade Agreement (NAFTA) using an applied general-equilibrium model. Domestic-content provisions bear most heavily on firms that use a high proportion of imported inputs. Indeed, the inequality nature of the constraint means that it does bind at all on certain firms, typically firms headquartered within the trade block. A principal point of this paper is that this discriminatory nature of such restrictions generates anti-competitive and rent-shifting effects when the industry in question is oligopolistic in nature. Firms unaffected by the content restriction are helped to the extent that their rivals are hurt, an effect of no particular significance or meaning in traditional competitive models. The anti-competitive effect tends to worsen welfare within the trade block while the rent-shifting effect tends to improve welfare, to the extent that the favored firms are owed within the block and rents are not dissipated through entry.

Because of the anti-competitive nature of a content restriction, it is possible that it reduces welfare within the trade block, even if it shifts demand to domestic substitute products produced with increasing returns by imperfectly competitive industries. Furthermore, it is even possible that a content restriction reduces the equilibrium output of the substitute domestic intermediate inputs, and thus fails to protect an industry it is suppose to help (although the main idea may be to aid the domestically-owned final goods producers as just noted). This outcome is more likely when the anticompetitive scale effect reducing output of the final good is large, and when the imported intermediates are poor substitutes for the domestic intermediates (Lopez-de-Silanes, Markusen, and Rutherford $(1994 a, b))$. This outcome is 
also more likely to the extent that the foreign multinationals can respond to the content restriction by switching from producing within the block to exporting to the block.

The following section of the paper explores the theoretical underpinnings of content restrictions by developing intra-firm shadow prices, a method that closely relates to the actual computational model that follows later. Section three then presents a very simple "mini-model" of a two-firm oligopoly in which there are two inputs, a domestic and an imported input. The "foreign" firm (producing as a multinational within the country) has an initial import share that exceeds that allowed by the content restriction while the content restriction for the "domestic" firm is non-binding. A simple numerical example at the end of that section illustrates the possibility that the content restriction can actually reduce the use of the domestic intermediate input and increase total duopoly profits (the domestic firm is helped more than the foreign firm is hurt).

Section four then presents the numerical general-equilibrium model of the North American auto industry, and calculates the effects of NAFTA relative to the current status quo, and then calculates the effects of adding the proposed content restriction to the free-trade area. Results from our central case are consistent with the theoretical ideas and possibilities developed earlier. The profits of the NA firms rise while those of the ROW firms fall, total output of autos in the NAFTA countries falls, and at least for some parameterizations, the output of North American auto parts falls. 
2. Domestic-Content and Trade-Balance Premia: Intra-Firm Shadow Prices

This section develops the notion of intra-firm shadow prices as a tool to both conceptually model and numerically estimate the effects of domesticcontent restrictions.

In the case of the full model developed in section four, there are two types of firms, North American (NA) and rest of world (ROW), also referred to as "domestic" and "foreign" throughout the paper. Throughout this and the next section, we will be referring to production within the regional trade block when we refer to the ROW or foreign firms, and will not discuss imports into the block. In the full model, both NA and ROW firms can substitute production across regions, both within and outside of the block. The firm types NA and ROW are distinguished only by their shares of inputs from different countries and by their output supply patterns. There is no explicit discrimination within the trade block against ROW firms, but their higher shares of imported inputs will create de facto discrimination as we suggested above.

In line with the empirical model to follow later, we will use the auto industry as our underlying example. The intermediate inputs are called parts and engines. A domestic or regional content ratio for autos is defined as the sum of the value of parts and engines (at tariff inclusive prices) from within the content region, divided by the sum of the value of all parts and engines (at tariff inclusive prices used in the autos). In the case of the proposed NAFTA, the definition will also include value added from labor. Let $V Z_{\mathrm{l}}$ and $V E_{\mathbf{k}}^{j}$ denote the value of parts and engines respectively shipped by type $j(j=$ $\mathrm{NA}, \mathrm{ROW}$ ) firms from country $\mathrm{k}$ to country $\mathrm{i}$. Let $\mathrm{TZ}_{\mathrm{ki}}$ and $\mathrm{TE}_{\mathrm{ki}}$ denote the tariff rates on parts and engine trade respectively from country $k$ to country i. Let $c$ denote the content region $(c=\{C A N, M E X, U S A\})$. Let $\mathrm{VA}_{\mathrm{ci}}^{\mathrm{j}}$ 
denote the value-added in engine and auto assembly by firm $j$ in region $i$ which is included in the domestic content calculation for region c. ${ }^{1}$ Finally, let $\gamma_{c}$ denote the minimum statutory regional content for firms producing in region c. Minimum domestic content restrictions are then represented by:

$$
\frac{V A_{c i}^{j}+\sum_{k \in c} V Z_{k i}^{j}\left(1+T Z_{k i}\right)+\sum_{k \in c} V E_{k i}^{j}\left(1+T E_{k i}\right)}{V A_{c i}^{j}+\sum_{k} V Z_{k i}^{j}\left(1+T Z_{k i}\right)+\sum_{k} V E_{k i}^{j}\left(1+T E_{k i}\right)} \geq \gamma_{c}
$$

for firms $\mathrm{j}=\mathrm{NA}, \mathrm{ROW}$, regions $\mathrm{i}, \mathrm{c}=\{\mathrm{CAN}, \mathrm{MEX}, \mathrm{USA}\}, \mathrm{k}=$ (CAN,MEX,USA,ROW\}. Under NAFTA, domestic content will include the labor component of value-added in auto assembly as well as parts and engines inputs, while under the existing CAFTA and MEX rules, $\mathrm{VA}_{\mathrm{ci}}^{\mathrm{j}}=0$.

Value-added, parts and engines used in country $i$ and produced within the content region appear in both the numerator and denominator of (1). Let $n$ index countries which are not members of content region c. Equation (1) can then be written as

$$
\begin{gathered}
\left(1-\gamma_{c}\right)\left[V A_{c i}^{j}+\sum_{k \in c} V Z_{k i}^{j}\left(1+T Z_{k i}\right)+\sum_{k \in c} V E_{k i}^{j}\left(1+T E_{k i}\right)\right] \\
-\gamma_{c}\left[\sum_{n \notin c} V Z_{n i}^{j}\left(1+T Z_{n i}\right)+\sum_{n \in c} V E_{n i}^{j}\left(1+T E_{n i}^{j}\right)\right] \geq 0
\end{gathered}
$$

1 The NAFTA is likely to include some portion of value-added in auto assembly along with domestic parts and engines inputs in the calculation of domestic content, whereas in the existing content regions (CAFTA and MEX) only parts and engines are relevant. We account for this distinction in the modelling. 
Equation (2) is a constraint in the general programming problem giving an auto firm's optimization problem. Let $\mu_{\mathrm{ci}}^{\mathrm{j}}$ be the Lagrangean multiplier associated with this constraint for firm type $\mathrm{j}$ operating in region $\mathrm{i}$ $\in \mathrm{c.}^{2}$ Let the price of parts in region $\mathrm{k}$ be denoted $\mathrm{p}_{\mathrm{zk}}$. Let $\hat{p}_{z k i}^{j}$ denote the shadow price (inclusive of tariffs and content premia) to type $j$ auto firms in region $i(i \in c)$ of parts produced in region $k(k=i$ included as a special case). These prices are given by $\left(1+T Z_{k i}\right) p_{z k}$ plus the shadow content premia equal to $\mu_{\mathrm{ci}}^{\mathrm{j}}$ times the derivative of (2) with respect to the part in question. This shadow price depends upon whether $\mathbf{k} \epsilon \mathrm{c}$, as follows:

$$
\hat{p}_{z k}^{j}=\left\{\begin{array}{cr}
\left(1-\left(1-\gamma_{c}\right) \mu_{c i}^{j}\right)\left(1+T Z_{k i}\right) p_{z k} & \text { if }(k, i) \in c \\
\left(1+\gamma_{c} \mu_{c i}^{j}\right)\left(1+T Z_{k i}\right) p_{z k} & i \in c, k \notin c
\end{array}\right.
$$

These results are intuitive. The effect of the content rule is reduce the shadow price or "user cost" of parts from within the content region because they effectively loosen the constraint (recall that country i's own parts, $k=i, T_{i i}$ $=0$, are necessarily included in the content region; in the case of Mexico's existing content region, only domestic parts are from the content region MEX). On the other hand, parts from outside the content region have their

2 The shadow prices associated with content region $c$ need not be equal across all regions $i \in c$. That is to say, the extent to which a $62.5 \%$ NorthAmerican content provision affects input choice need not have the same degree of distortion in Mexico as in Canada. 
supply prices raised by the content rule (1).

The same pricing relationships hold for engines. However, unlike parts which are modelled as differentiated in our full model, engines are assumed to be homogeneous within a firm type. Engines may be produced by a single firm in more than one country, so in equilibrium their shadow marginal costs (inclusive of tariffs and premia) are equated across countries between which engines are shipped. Let $p_{c k}^{j}$ denote the marginal cost of production of an engine in region $k$ by a type $j$ firm, and suppose that region $\mathrm{k}$ engines are shipped to region $\mathrm{i}$. Then the shadow marginal costs (user costs) in region $i, \hat{p}_{a i}^{j}$, are given by

$$
\hat{p}_{e i}^{j}=\left\{\begin{array}{cr}
\left(1-\left(1-\gamma_{c}\right) \mu_{c i}^{j}\right)\left(1+T E_{k i}\right) p_{c k}^{j} & \text { if }(k, i) \in c \\
\left(1+\gamma_{c} \mu_{c i}^{j}\right)\left(1+T E_{k b}\right) p_{e k}^{j} & i \in c, k \notin c
\end{array}\right.
$$

The general results suggested here are intuitive. The content rules raise the shadow costs of parts and engines sourced from outside the region and lower the shadow costs of those from within the region. The examination of the shadow prices suggests that the imposition of a binding content rule in a freetrade area should lead to a larger equilibrium level of production for inputs produced within the region. But there are several subtle effects which are not well captured by a simple inspection of the shadow prices. In particular, the 
shadow prices give us intuition about relative input prices and substitution effects, but they suggest little about firm scale effects. As we shall argue in the next section, the content provisions in the case of NAFTA discriminate against ROW firms, and hence (ceteris paribus) lower their outputs and profitability. But in an oligopolistic industry, this has an anti-competitive effect, and it is entirely possible that total industry output will fall significantly and profits could be shifted to the domestic (NA) firms. Indeed it is possible for the anti-competitive scale effect to be sufficiently strong that it outweighs a substitution effect in favor of domestic inputs, especially if the domestic inputs are imperfect substitutes for imported inputs. Alternatively, if the marginal costs to the foreign firms of serving the content region by exports is not much higher than their initial marginal cost of producing within the block, the imposition of the content restriction may simply induce the foreign firms to switch to exporting to the block. Depending on the costs of exporting, this may largely mitigate the anti-competitive and rent-shifting effects of the content restriction leaving only a significant decrease in the demand for the domestic intermediate inputs. 


\section{Content Restrictions in a Simple Duopoly Model}

In this section, we present a highly simplified "mini-model" of our numerical model in order to capture the intuition behind our principal results. Suppose that there are two producers within the home country of a final good $\mathrm{X}$ (autos), labeled $\mathrm{h}$ (home) and $\mathrm{f}$ (foreign). The two firms each use a homecountry input $\left(Z_{h}\right)$ and a foreign input $\left(Z_{f}\right)$, but the foreign firm is more dependent on the imported input. $Z_{i j}$ will denote the use of input $i$ by firm $j$ $(i, j=h, f)$. In particular, we model the firms' production functions as CobbDouglas, which means that the two inputs are not particularly good substitutes.

$$
X_{h}=Z_{h h}^{\alpha} Z_{f h}^{(1-\alpha)} \quad X_{f}=Z_{h f}^{\beta} Z_{f f}^{(1-\beta)}
$$

We assume that $\alpha>\beta$, indicating that each firm type is more dependent on its domestic input. Let $q_{h}$ and $q_{f}$ denote the prices of $X_{h}$ and $X_{f}$ respectively. These prices will be held constant throughout the analysis. The domesticcontent restriction requires that the value of the home-country input divided by the total value of inputs be greater than or equal to $\gamma$.

$$
\frac{q_{h} Z_{h i}}{q_{h} Z_{h i}+q_{f} Z_{f i}} \geq \gamma
$$


We assume that $\alpha>\gamma>\beta$ so that the domestic-content restriction is binding on the foreign firm but not on the home firm (recall that with the CobbDouglas function, $\alpha$ and $\beta$ give the value shares of the domestic input for the home and foreign firm respectively). We can then solve for the unconstrained cost function for the home firm and the constrained (by equation 6) cost function for the foreign firm. These are given by

(7) $C_{h}=\left[\alpha^{-\alpha}(1-\alpha)^{\alpha-1}\right] q_{h}^{\alpha} q_{f}^{1-\alpha} X_{k}$ $C_{f}=\left[\gamma^{-\beta}(1-\gamma)^{\beta-1}\right] q_{k}^{\beta} q_{f}^{1-\beta} X_{f}$

It can be shown that $\mathrm{C}_{\mathrm{f}}$ is increasing in $\gamma$ for $\gamma>\beta$ (the content restriction is binding). Demands for the home-country input by the home and foreign firms respectively are given as follows (note that $Z_{h f}$ is not give by he derivative of $C_{f}$ with respect to $q_{h}$ since $Z_{h f}$ is not chosen to minimize $C_{f}$ ).

$$
Z_{h h}=[\alpha /(1-\alpha)]^{1-\alpha}\left(q_{f} / q_{h}\right)^{1-\alpha} X_{h}
$$

$$
Z_{h f}=[\gamma /(1-\gamma)]^{1-\beta}\left(q_{f} / q_{h}\right)^{1-\beta} X_{f}
$$

Let $c_{b}$ and $c_{f}$ denote unit cost functions. Assume that demand is represented by a simple linear demand curve. Profits (ignoring fixed costs) for the two firms are give by 


$$
\begin{gathered}
\pi_{i}=p\left(X_{h}+X_{f}\right) X_{i}-c_{i} X_{i} \quad c_{i}=C_{i} / X_{i}, \quad i=(h, f) \\
p\left(X_{h}+X_{f}\right)=a-b\left(X_{h}+X_{f}\right)
\end{gathered}
$$

Now assume that each firm behaves in a Cournot fashion, maximizing (10) taking its rival's output as fixed. The first-order conditions yield reaction curves which can then be solved to yield the Cournot outputs.

$$
X_{h}=\left(a-\left(2 c_{k}-c_{f}\right)\right) / 3 b, \quad X_{f}=\left(a-\left(2 c_{f}-c_{h}\right)\right) / 3 b
$$

Substituting for $c_{h}$ and $c_{f}$ from (7), we can differentiate the outputs with respect to $\gamma$ to get the responses of the firm's outputs to a change in the domestic content ratio (continuing to assume that the content ratio falls in the range $\alpha>\gamma>\beta$ ).

$$
d X_{h} / d \gamma=\left[c_{f} / 3 b\right] \frac{\gamma-\beta}{\gamma(1-\gamma)} \quad d X_{f} d \gamma=-\left[2 c_{f} / 3 b\right] \frac{\gamma-\beta}{\gamma(1-\gamma)}
$$

The equations in (12) indicate that total output of $X$ falls with an increase in the content ratio. $X_{h}$ rises while $X_{f}$ falls by twice that amount. This indicates the anti-competitive nature of the content restriction. The rentshifting aspect of the content restrictions can be shown by solving for the profit functions of the firms using (10) and (11). 
(13)

$$
\pi_{i}=\frac{1}{9 b}\left[a-\left(2 c_{i}-c_{j}\right)\right]^{2}=b X_{i}^{2}
$$

Differentiating these profit functions using (12) gives us the change in profits due to an increase in the content restriction.

$$
\frac{d \pi_{h}}{d \gamma}=2 b X_{k}\left(c_{f} / 3 b\right) \frac{\gamma-\beta}{\gamma(1-\gamma)}, \quad \frac{d \pi_{f}}{d \gamma}=-4 b X_{f}\left(c_{f} / 3 b\right) \frac{\gamma-\beta}{\gamma(1-\gamma)}
$$

The equations in (14) give us the intuitive result that profits for the home firm increase and the profits for the foreign firm decrease following a tightening of the content restriction. We see that it is possible that the total profits of the two firms increase, a case that occurs when $X_{h}>2 X_{f}$.

Now turn to the demand for the domestic input $Z_{h}$. In order to simply the notation a bit, choose units such that all prices are one initially, $\mathrm{q}_{\mathrm{i}}$ $=1$. Differentiate (8) and (9) using (12) and sum the two results to get the overall change in demand for $\mathrm{Z}_{\mathrm{h}}$. This is given by

$$
d Z_{h} / d \gamma=\left[(\alpha /(1-\alpha))^{1-\alpha} \frac{1}{3 b}-(\gamma /(1-\gamma))^{1-\beta} \frac{2}{3 b}+(1-\beta) \frac{\gamma}{\gamma-\beta}\right] \frac{\gamma-}{\gamma(1}
$$

There are three terms in the expression in brackets in (15). The first is 
$\mathrm{dZ}_{\mathrm{hh}} / \mathrm{d} \gamma$ and gives the expanded demand by firm $\mathrm{h}$ for the domestic input due to the contraction in the output by the foreign firm. The second term is the change in the demand for $Z_{h f}$ due to the fall in $X_{f}$. These first two terms can thus be thought of as "scale" effects due to the change in outputs. The third term in (15) is the derivative of (9) with respect to $\gamma$ holding $X_{f}$ constant. This is the "substitution" effect in which, at constant output, the foreign firm substitutes $X_{h}$ for $X_{f}$. The first and third terms are positive while the second term is negative.

The question of whether or not $\mathrm{dZ}_{\mathrm{h}}$ can be negative turns on the following condition derived from (15).

$$
d Z_{h}<0 \text { iff }[\alpha /(1-\alpha)]^{1-\alpha}-2[\gamma /(1-\gamma)]^{1-\beta}+3 b(1-\beta) \gamma /(\gamma-\beta)
$$

The possibility that the domestic content restriction can fail to protect the domestic input is more likely to occur when $\beta$ and $\gamma$ are relatively large and $\mathrm{b}$ is relatively small.

Table one presents a simple example of the possible effects of imposing a domestic-content restriction using the values off $\alpha, \beta$, and $\gamma$ drawn from our actual data. Results are related to those presented later for the full model. The first set of numbers shows that the home firm's output rises, the foreign firm's output falls, and total industry output falls. The second set of 
numbers shows the same sign pattern for the change in the use of $Z_{h}$. We should note that the fall in total industry $X$ and $Z_{h}$ is not robust to the specification of the parameters, and depends in particular on the fact that $h$ has more than $3 / 4$ of the market (but that is certainly consistent with the autos model). The final set of numbers in Table 1 look at profit figures, and here we see the somewhat surprising result that the profit gains to the home firm outweigh the profit loss to the foreign firm. This is a consequence of the anticompetitive nature of the content restrictions resulting in a lowering of the industry output of $\mathrm{X}$.

We can also relate this numerical example to equations (3) and (4), and think of $\gamma \mu_{\mathrm{c}}$ and $(1-\gamma) \mu_{\mathrm{c}}$ as implied ad valorem "tax" and "subsidy" rates on the use of the foreign and domestic inputs respectively for the foreign firm. We can use the fact that at actual prices, the value shares of the of the inputs into $X_{f}$ are given by $\gamma$ and $(1-\gamma)$, while at shadow prices the value shares are given by $\beta$ and $(1-\beta)$.

$$
\frac{q_{f} Z_{f f}}{q_{h} Z_{k f}}=\frac{1-\gamma}{\gamma} \quad \frac{\hat{q}_{f} Z_{f f}}{\hat{q}_{h} Z_{k f}}=\frac{q_{f}\left(1+\gamma \mu_{c}\right) Z_{f f}}{q_{h}\left(1-(1-\gamma) \mu_{c}\right) Z_{h f}}=\frac{1-\beta}{\beta}
$$

Working backwards, we can recover $\mu_{\mathrm{c}}$ and the "tax" and "subsidy" rates reported in Table 1. The two equations of (17) can be used to demonstrate that the sum of the content premia (the sum of the "tax" and "subsidy" 
payments) is zero.

Finally, we emphasize that this simple example does not allow the foreign firm the option of switching to exports and reducing or eliminating production in $\mathrm{h}$. This is of some importance in our empirical model, where ROW firms are initially both producing within NA and exporting to it. Thus initially, delivered marginal costs to the NA market from the two sources of supply are equal, and it is costless at the margin to substitute one unit of imports (exports from ROW) for one unit of production within North America.

This increases the likelihood that the content rule will fail to protect North American producers of parts and engines. 
Table 1: A Numerical Example Using the Mini-Model

Initial Parameter Values: $\mathrm{a}=3.0, \quad \mathrm{~b}=0.3, \quad \alpha=0.968 \quad \beta=0.528$ $\gamma=0.625$

Counterfactual Experiment: impose the content restriction $\gamma=0.625$

Percentage Change in Output of X:

Home Firm

1.5

Foreign Firm

$-49.7$

Industry

$-1.4$

Percentage Change in Demand for $Z_{h}$ :

$\begin{array}{lr}\text { Home Firm } & 1.5 \\ \text { Foreign Firm } & -39.3 \\ \text { Industry } & -0.7\end{array}$

Percentage Change in Profits:

$\begin{array}{lr}\text { Home Firm } & 2.9 \\ \text { Foreign } & -74.7 \\ \text { Industry } & 2.7\end{array}$

Implied ad valorem tax on imported inputs for the foreign firm: $\gamma \mu_{c}=0.259$ Implied ad valorem subsidy on domestic inputs for the foreign firm: $(1-\gamma) \mu_{c}=0.155$ 


\section{Specification of the Applied General-Equilibrium Model}

In this section, we will develop the formal model, including the assumptions concerning technology, pricing behavior, ownership and the structure of final demand.

\section{(A) Trading Regions and Content Regions}

The model consists of four regions: Canada (CAN), the United States (USA), Mexico (MEX), and the rest of the world (ROW). Each of these regions generates final demands which are modelled through the representative agent paradigm. The model is based on a conventional general equilibrium structure in which demand functions are uncompensated - income from factors of production and taxes are allocated to expenditures for final commodities.

The model pays special attention to the structure of intra-regional trade in autos and related goods (parts and engines). The majority of auto imports from ROW into North America come from Japan, while North American exports to ROW are spread among a larger number of countries. These exports are of very minor significance, so we do not feel that the aggregate of the rest of the world plays an important role.

In this model, "content regions" refer to trade blocks within which domestic content provisions may apply. In the initial data, Mexico is a content region, and CAFTA (Canadian-American free-trade area) is a second content region. Content region NAFTA (North American free-trade area) adding Mexico to CAFTA is created by counterfactual experiment, and various content rules can be examined for that region. Further discussion of content rules and content regions are postponed until the next section.

(B) Produced Goods

There are two final goods, and four produced goods in total in the model. A composite good called $\mathrm{Y}$ is an aggregate of all non-auto goods. $\mathrm{Y}$ amounts to about $97 \%$ of GDP in the North American economies. Autos are the second final good. Parts and engines are the remaining two produced 
goods, and are inputs into auto production.

(C) Primary Factors

There is one composite factor, which we will refer to as "labor," which is perfectly mobile across sectors within countries, but perfectly immobile across countries. Capital inputs to the composite $\mathrm{Y}$ sector are perfect substitutes for capital inputs to auto parts production.

The three auto goods are produced with region-specific labor inputs and with capital endowments specific by region and firm to cars and engines. If the initial capital values are held fixed, we have in essence short run experiments in which plant capacities are limited. The model allows for capital to be transformed between auto sector goods and regions, holding aggregate capital stocks constant within each firm. The elasticity of transformation is a choice parameter of the model. The higher the value of this elasticity, the easier it is, for example, to transform auto production capital in the USA into engine production capital in Mexico. As the auto sector expands in a given region, it draws labor from the composite sector, raising the marginal product of labor in that sector, and hence raising the wage of labor in the auto sector. The strength of this general-equilibrium effect limits the expansion of the auto sector following trade liberalization, and can be specified in the calibration procedure discussed later in the paper. The magnitude of this effect is one of the major empirical unknowns of this paper.

\section{(D) Firm Types}

There are two types of auto firms in the model. The data on the big three US owned firms are averaged, giving us three symmetric "North American firms" (NA). All other firms are made symmetric by a similar averaging process, and these are referred to as "ROW (or foreign) firms." Both types of firms have production in all three North American countries, and there is no explicit policy discrimination between types. The two types of firms are distinguished by their import and export behavior. USA (North 
American) firms do little importing or exporting outside of North American, and their cars have a high North American parts and engine content. ROW (foreign) firms import a great deal into North America in addition to their local production, and have a much lower North American content for their local production. Thus a high North American content rule can indirectly discriminate against foreign firms as we suggested in the previous section.

(E) Ownership

Auto firms own plants in different countries and thus coordinate their production, pricing, and sales decisions across their plants. Auto firms also own the engine plants, so engines are supplied to the auto firms at marginal cost. One engine is required per car. The parts sector is much more complex in reality, with the auto firms both producing parts and purchasing parts from literally hundreds of large and small independent suppliers. Our modelling decision is to treat parts producers as independently owned. The (large) auto producers are able to segment markets, so arbitrage conditions need not bind across markets. This assumption is consistent with our price data. The (small) parts producers are not able to segment markets.

The regional pattern of firm ownership (i.e. the allocation of net capital returns) is exogenous, and the capital stock and ownership pattern remains constant through the analysis.

(F) Technology, Pricing, and Entry/Exit in the Auto Industry

Production in the auto industry is characterized by increasing returns to scale. Production cost for a type $j(j=N A, R O W)$ firm in market $i$ is given by a constant marginal cost of production (for a given price of labor and capital) times output plus a fixed cost (fci). The total cost for a type $j$ firm production in region $i$ is denoted $C_{i}^{j}$, with shadow marginal cost (i.e., production cost plus the shadow premia (whether positive or negative) due to content and trade-balance restrictions) denoted $\mathrm{mc}_{1}$. 


$$
C_{i}^{j}=m c_{i}^{j} * X_{i}^{j}+f c_{i}^{j}, \quad a c_{i}^{j}=C_{i}^{j} / X_{i}^{j}=m c_{i}^{j}+f c_{i}^{j} / X_{i}^{j}
$$

where aci is average cost and $X_{i}^{j}$ is output of a $j$-type firm in market $i$. Firm type $\mathrm{j}$ sets a markup $\mathrm{m}_{1}^{\mathrm{j}}$ in market $\mathrm{i}$, so pricing equations are written:

$$
p_{x i}^{j}\left(1-m_{i}^{j}\right)=m c_{i}^{j}
$$

where $p_{x i}^{j}$ is the consumer price of type $j$ autos in market $i$. All type $j$ firms in a market are assumed to have the same price initially, but their products may or may not be perfect substitutes. Joint maximization by firm type $j$ across markets further dictate that, if the firm ships to market $i$ from market $k$, the firm sets the same market $i$ markup $m_{i}^{i}$ on that shipment. We assume that initially, firm profits equal zero. This is made operational by assuming zero profits at the plant level. That is, no copy of an additional plant (same output, shipments, prices, and markups as existing plants) can make positive profits. For a plant located in market $\mathbf{k}$ and shipping to some or all of the three NA countries, this condition is given by (20)

$$
\sum_{i} p_{x i}^{j} m_{i}^{j} X_{k i}^{j}=f c_{k}^{j} \quad i, k=(C A N, U S A, M E X, R O W), \quad j=(U S A, R C
$$

The model is designed to allow us to perform two types of counter-factual experiments. In one, we can how the number of firms fixed and so see how firm profits are affected. In the second, we allow entry and exit to occur until 
profits are once again zero (the number of firms is treated as a continuous variable).

Our input data give us $p_{x i}^{j}, X_{i}^{j}, X_{k i}^{j}$, and $\epsilon_{1}^{j}=a c_{1}^{j} / m c_{1}^{j}, \epsilon$ being the elasticity of scale in production. Our calibration program then solves the system of 27 equations (18), (19), and (20) to obtain calibrated values of the 27 unknowns: $\mathrm{mc}_{1}^{j}, \mathrm{~m}_{\mathrm{j}}^{\mathrm{j}}$, and $\mathrm{fc}_{1}^{j}$. Data and details are found in Lopez-deSilanes, Markusen, and Rutherford (1994a,b).

An important problem in this class of models is the choice of imperfectly competitive behavior. The approach that we have chosen is basically a Cournot markup formula, in which firms view other firms outputs as constant, multiplied by a "conjecture parameter" which is calibrated to the benchmark market shares and thereafter held constant in the analysis. At the top level, or "nest" of the utility function, autos and the composite commodity are Cobb-Douglas substitutes. At the next level, autos are divided into aggregates of NA and ROW cars. In the lowest nest, there is a constant elasticity of substitution in demand (possibly infinite) between autos from two firms of the same type. Let $\sigma_{\mathrm{r}}$ be the elasticity of substitution in demand for autos of different firm types $(r=N A$, ROW $)$. Let $\sigma_{\mathrm{f}}$ be the elasticity of substitution between cars produced by firms within the same type (e.g., the elasticity of substitution between Fords and GM models). We assume that these elasticities are common across regions. Let $\theta \mathrm{i}$ denote the share of type $\mathrm{j}$ firms in total auto sales in market $i$. Let $n_{1}^{j}$ denote the number of type $j$ firms 
producing in market i. ${ }^{3}$ The optimal Cournot markup $\left(\tilde{m}_{i}^{j}\right)$ for a type $\mathrm{j}$ firm in market $i$ is given by the formula ${ }^{4}$

$$
\tilde{m}_{i}^{j}=\frac{1}{\sigma_{f}}+\left[\frac{1}{\sigma_{r}}-\frac{1}{\sigma_{f}}\right] \frac{1}{n_{i}^{\prime}}+\left[1-\frac{1}{\sigma_{r}}\right] \frac{\theta_{i}^{j}}{n_{i}^{\prime}}
$$

We employ a "conjecture parameter" $\Omega_{1}^{j}$ which reconciles the markups predicted by Cournot competition (21) with the calibrated benchmark values $\mathrm{m}$ i obtain from the solution to (18), (19), and (20).

$$
m_{i}^{j}=\Omega_{i}^{j} \tilde{m}_{i}^{j}=\alpha_{i}^{j}\left[\frac{1}{\sigma_{f}}+\left[\frac{1}{\sigma_{r}}-\frac{1}{\sigma_{f}}\right] \frac{1}{n_{i}^{j}}+\left[1-\frac{1}{\sigma_{r}}\right] \frac{\theta_{i}^{j}}{n_{i}^{j}}\right]
$$

The calibrated markups for firm $j$ in market $i$ is thus exactly consistent with Coumot pricing if $\Omega_{1}^{j}=1$. Throughout the simulations presented later in the paper, $\sigma_{\mathrm{r}}$ and $\sigma_{\mathrm{f}}$ are held at 10.0 . The values of $\Omega_{\mathrm{i}}^{\mathrm{j}}$ vary with the choice of $\sigma_{\mathrm{f}}$, but generally speaking, $\Omega_{1}^{j}$ is less that one for NA firms in Canada and the US, and greater than one in Mexico. For foreign (ROW) firms, $\Omega_{1}^{j}$ is about 1.0 in the US, about 2.0 in Canada, and about 4.0 in Mexico. This suggests that smaller markets are inherently more collusive, and that a group of firms with

${ }^{3}$ In the markup formulae, we use the number of firms producing in a given market as a proxy for the number of firms selling in a given market.

4 Appendix A in Lopez-de-Silanes, Markusen, and Rutherford (1994b) contains the derivation of this markup equation. 
a smaller market share (the ROW firms) are more collusive than a group with a larger market share (USA firms).

In our simulations, the calibrated values of $\Omega_{i}^{i}$ are held constant throughout the counterfactual experiments, but the markups vary endogenously as the firms' individual numbers and market shares changes. Increased competitiveness (lower markups) due to loss of market share is an important potential source of gains due to trade liberalization in our model. When we allow free entry and exit, lower markups are only consistent with higher firm scale, implying increased technical efficiency in addition to lower consumer prices.

(G) Technology and Pricing in the Parts Sector

The parts sector $\mathrm{Z}$ is assumed to be monopolistically competitive, with product differentiation by firm. While the multinational car producers certainly have significant parts production, there are a great many small producers as well (about 500 in Mexico, 2300 in the US). We thus make the modelling choice that parts producers are treated as small, independent, national firms. We will exposit just a two-region example to show how the parts sector works. Domestic and foreign composite parts $\mathrm{Z}$ and $\mathrm{Z}^{*}$ are composed of the individual underlying parts from each country $\left(\mathrm{Z}_{\mathrm{i}}, \mathrm{Z}_{\mathrm{i}}^{*}\right)$, and these are in turn aggregated into a single composite $Z_{c}$. 


$$
Z_{c}=\left[Z^{\beta}+Z^{* \beta}\right]^{\frac{1}{\beta}} \quad Z=\left[\sum_{i}^{n} Z_{i}^{\beta}\right]^{\frac{1}{\beta}}
$$

Let $\mathrm{p}_{\mathrm{z}}$ denote the domestic price of the domestic parts composite $\mathrm{Z}$. Any part produced within that country will be produced in the same amount and priced the same, so we can deal with a representative part (imported parts will generally be priced differently). It is assumed that the small parts producers cannot segment markets, so arbitrage constraints hold and we need only consider the

domestic price received on both domestic and export sales. We assume that parts are produced using only capital and labor (no purchased domestic or imported parts), and thus the trade-balance and domestic content provisions are not relevant to parts producers. The price received by an individual domestic parts firms, $p_{z i}$, is the marginal product of $Z_{i}$ in producing $Z$. The revenue of the producer is then $\mathrm{p}_{\mathrm{zi}} \mathrm{Z}_{\mathrm{i}}$. These are given by

$$
p_{z_{i}}=p_{z}(1 / \beta) Z^{1-\beta} \beta Z_{i}^{\beta-1} \quad R_{z_{i}}=p_{z_{i}} Z_{i}=\left[p Z^{1-\beta}\right] Z_{i}^{\beta}
$$

We make the usual monopolistic-competition assumption that each domestic parts producer views itself as small in the market, so that $Z$ and $p_{z}$ are viewed as constant. Hence the bracketed term in the second equation of $(7)$ is viewed as constant. Marginal revenue for an individual domestic parts producer is thus given by

$$
M R_{z_{1}}=d R_{z_{i}} / d Z_{i}=\left[p Z^{1-\beta}\right] \beta Z_{i}^{\beta-1}=p_{z_{i}} \beta
$$

Price is a constant markup over marginal cost. We assume the same type of cost function that we did for auto producers: a fixed cost plus a constant 
marginal cost. Free entry produces zero profits: price equals average (production) cost. Together these give us

$$
\left[p_{z} \beta=m c_{z}, p_{z_{i}}=a c_{z}\right] \rightarrow \epsilon_{z} \equiv a c_{z} / m c_{z}=1 / \beta
$$

where $\epsilon_{\mathrm{z}}$ is the elasticity of scale in parts production. Our data estimates of these elasticities give us estimates for the substitution parameter $\beta$ for each country's parts composite (i.e., these vary across countries).

We assume that parts producers used capital and labor in the same proportions in fixed and variables costs. ac/mc is then independent of factor prices and depends only on the level of production $Z_{\text {. }}$. In the usual parable, the parts industry expands through the addition of new firms at constant scale within each country (Helpman and Krugman (1985) provide extensive discussions of this type of model). Apply a similar proceedure to the foreign country. The production functions for the two parts composites can then be written as

$$
Z=n^{1 / \beta} Z_{i} \quad Z^{*}=\left(n^{*}\right)^{1 / \beta^{*}} Z_{i}^{*}
$$

where $Z_{i}$ and $Z_{i}^{*}$ are constants. We thus have convenient "industry" production functions for the parts composite of each country in (10), with that production function homogeneous of degree $1 / \beta_{i}>1$ in country $i$. We use this simplification in computing the solution to the model. (In forming $Z_{c}$ in (6) from $\mathrm{Z}$ and $\mathrm{Z}^{*}$, the same value of $\beta$ is used as is used in constructing $\mathrm{Z}$. $\beta^{*}$ 
is similarly drawn from data on the elasticity of scale in the other country, and is used in forming $Z_{c}^{*}$ as well as $Z^{*}$.)

\section{(H) Technology and Pricing in Engines}

As noted above, technology is naturally restricted to one engine per car. $^{5}$ It is also true that engine trade in almost entirely intra-firm. Since firms within a given type (NA, ROW) are identical, we therefore have two types of engines, NA and ROW. NA engines are exclusively used in NA car and similarly for ROW cars and engines. Because engine sales are intra-firm, the relevant price is the marginal cost of supply (i.e., trade balance and domestic content premia are included in the auto firms' assessments of the costs of different sources of supply). There are a number of difficulties incorporating scale economies in engine production into this overall production structure, one of which is the marginal-cost-pricing rule. In this version of the model, we have ignored scale economies in engine production, and modelled engines as produced by capital and labor at constant cost.

\section{(I) The Structure of Final Demand}

Final demand in each region arises from budget-constrained utility

${ }^{5}$ There is a caveat. In our benchmark calibration, the technology for auto production is not constant across countries, and, specifically, the value share of engines in auto cost is different in the US and Mexico. For this reason, even though engines enter as a fixed-coefficient input to auto production within each region, because production effects change the share of various regions in aggregate supply, the world-wide engine production and auto production need not move one for one. 
maximization by a representative agent. There are therefore two aspects to the demand functions - sources of income and underlying preferences. Income derives both from primary factor earnings and tax revenue. The representative consumer in each region is endowed with labor and three types of capital. The first type of capital serves as input to automotive parts and non-automotive production. The second and third types of capital are capital stocks associated with U.S. and ROW automotive firms, used in the production of engines and finished autos. Income also includes tariff revenue from parts, engines and auto trade.

Representative consumers demand two final goods: finished autos and non-automotive output. As noted above, the demand for autos incorporates differentiation between autos from different firm types. The top level nesting between autos and other goods implies that a constant fraction of income is spent on these two aggregates. 


\section{Counterfactual Experiments}

Data sources and the calibration procedure for the model are discussed in Lopez-de-Silanes, Markusen, and Rutherford (LMR) (1994b) and will not be repeated here. ${ }^{6}$ This paper moves beyond LMR (1994b) by presenting the theoretical analysis of content restrictions found in sections 2 and 3 and by performing a detailed counterfactual analysis of content restrictions, the results of which are reported in this section. In this section, we will begin from the NAFTA equilibrium calculated without the content rule in LMR (1994b), rather than begin from the status quo since our purpose here is to analyze the content rule rather than to analyze NAFTA per se. Detailed results for the experiment moving from the status quo to NAFTA are found in LMR (1994b).

Tables 2 and 3 report the results of most interest given the objectives of the paper. Table 2 presents the percentage changes in total North American production or employment when the content rule is imposed, using NAFTA without the content rule (from LMR 1994b) as the "revised benchmark" equilibrium. The lower panel of Table 2 reports results when the number of firms is fixed, and so changes in the return to capital are reported as well.

${ }^{6}$ The calibration procedure for the model is quite detailed. Copies of Lopez-de-Silanes, Markusen, and Rutherford are available from the authors, along with the model itself for those who are interested. The model is written in a new version of GAMS, which calls Rutherford's MPS/GE solver as a subsystem. 
We see in Table 2 that many of the changes in key quantities are consistent with some of the ideas developed in the theoretical sections of the paper. Total North American auto and parts production tends to fall as a consequence of the content rule, while engine production increases. Interestingly, total auto sector employment falls in North America, indicating that the content rule is not protecting North American auto employment. Profit figures have the

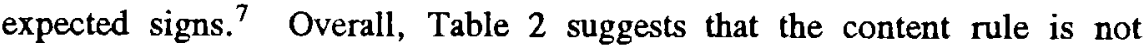
desirable. It causes a significant fall in auto production and employment with only a small benefit to the stockholders of the NA firms in the case where the number of firms is held fixed.

As suggested earlier in the paper, a key to understanding some of these results is the fact that the foreign firms respond to the content rule by substituting exports to North American replacing production within North America. This is advantageous for the ROW firms because, as we indicated following equation (19), the firms equate delivered marginal cost from ROW to the US with marginal cost of production within the US initially. The imposition of the content rule results in an increase of $13 \%$ in exports to NA by ROW firms with free entry and an increase of $18 \%$ with a fixed number of firms. This helps account for the fall in NA parts production. The transfer

${ }^{7}$ It is somewhat arbitrary how to interpret changes in profits when the firms have substantial non-North American operations. What we have done is divide profits for each firm type by the initial (benchmark) value of that firm's North American capital stock. 
of production from NA to foreign sources is eventually equilibrated through general-equilibrium factor-price effects, which raise the cost of production in ROW and lower the cost of production in NA.

Table 3 therefore computes the effects a content restriction with a voluntary export restraint (VER) imposed that sets ROW firm imports into NA at their NAFTA level. This prevents the ROW firms from circumventing the content rule by simply moving production off shore. In this case, we see substantially different results. We see a much smaller decrease in the output of autos and engines by the ROW firms, and a significant increase in their usage of parts. We see from Table 3 that the content restriction plus VER has a negative effect on the NA firms relative to the content restriction alone. For NA firms, the addition of the VER effectively causes output of autos, engines, the use of parts, and profits to fall relative to the content restriction alone. It is not entirely clear to us why this is the case, but one effect that is certainly operating is a general-equilibrium price effect through factor markets. In both the free entry and fixed number of firms cases, the ROW firms increase their usage of NA parts about $25 \%$ when the VER is added to the content restriction. Increased demand for labor and capital by the ROW firms raise factor prices for the NA firms. 
Table 2

\% Changes in North American Production and Employment

Experiment: Add the 62.5\% NA Content Rule to NAFTA (i.e., NAFTA without the Content Rule is the "Benchmark")

\section{Free Entry}

$\begin{array}{lccc} & \text { NA Firms } & \text { ROW firms } & \text { TOTAL } \\ \text { Auto Production } & 0.85 & -25.84 & -4.71 \\ \text { Engine Production } & 5.95 & 23.71 & 2.86 \\ \text { Parts Employment } & 0.45 & -8.34 & -0.55 \\ \text { Total NA Employment } & 1.58 & -16.86 & -0.78\end{array}$

Fixed Number of Firms

NA Firms ROW firms TOTAL

Auto Production

0.10

$-22.34$

$-4.62$

Engine Production

4.07

$-20.25$

1.39

Parts Employment

$-0.13$

$-4.35$

$-0.61$

Total NA Employment

0.68

$-13.11$

$-1.09$

Profits*

1.15

$-6.22$

$-0.11$ 


\section{Table 3}

\% Changes in North American Production and Employment

Experiment: Add the $62.5 \%$ NA Content Rule to NAFTA plus a VER on ROW Auto

Exports to NA in order to hold imports at NAFTA level

Free Entry

NA Firms ROW firms TOTAL

Auto Production

Engine Production

Parts Employment

Total NA Employment
$-2.63$

1.14

$-2.11$

$-1.82$

Fixed Number of Firms

NA Firms

$-2.67$

0.22

$-2.15$

$-2.01$

0.47
$-4.18$

$-3.83$

19.76

7.93

$-0.57$
Auto Production

Engine Production

Parts Employment

Total NA Employment

Profits*
ROW firms

$-3.63$

$-2.80$

20.33

8.43

$-2.31$
0.40

$-0.66$

TOTAL

$-2.78$

$-0.11$

0.00

"Profit figures give the change in total (world) firm profits divided by the initial value of auto capital owned by that firm type located in NA. 
There is similarly a general-equilibrium effect operating through the labor market in the case of autos and engines. The introduction of the VER leads the ROW firms to increase their NA output of autos and engines by about 18$20 \%$. Labor must be drawn from the composite sector at increasing cost, which adversely affects the NA firms. Thus while the imposition of the VER reduces total outputs and employment by less that with the imposition of the content rule alone, the VER fails to help the NA firms.

The addition of the VER to the content rule actually causes an increase in the profits of the ROW firms relative to the content rule alone. This is also a bit hard to understand. One possible explanation is reminiscent of Eaton and Grossman (1985). They note that when several firms are operating as Cournot competitors in a market, they are "over supplying" in the sense of selling too much to maximize their joint profits. In the context of their model, Eaton and Grossman show that the optimal policy is actually an export tax, which improves the export price of the product by restraining exports. While the sum of the firms' profits does not generally increase, the sum of the profits and government tax revenue does exceed the sum of the pre-tax profits. The profit figure reported in Table 3 returns the VER rents to the ROW firms, and so the result is consistent with Eaton and Grossman.

Perhaps more relevant, Harris (1985) and Krishna (1989) show that when foreign and domestic firms are Bertrand competitors, the imposition of a VER can raise the profits of both the foreign and the domestic firms. The reason is again that under Bertrand competition, the domestic and foreign firms are behaving in too competitive a fashion, and the VER serves a beneficial (from the producers' point of view) anti-competitive function. While the might help explain why the foreign firms actually benefit a very small amount from the VER, it does not explain why the NA firms are hurt a small amount. We expect that this is explained by the substitution of the ROW firms into NA production with the consequent effects on factor prices 
as we noted above. Overall, the results of Table 3 suggest that the imposition of the VER in addition to the proposed NAFTA content rule is not a good idea. It is estimated to have only a very small beneficial effect on employment relative to the content rule alone. NA firms shrink in output, employment, and indeed profits when the VER is added to the content rule.

Considering the combined policy of the content rule and the VER relative to NAFTA with neither (the benchmark), we see a very small profit for the NA firms (with no entry), but it reduces the auto outputs of both firm types and total employment. The anti-competitive effects are particularly evident in that this combined policy increases the profits of NA firms, but reduces their output.

In order to illustrate the sensitivity of the results to the level of the content rule, we re-ran the model with the content restriction raised by $5 \%$ to $67.5 \%$. Results are presented in Tables 4 and 5, corresponding to the experiments in Tables 2 and 3 respectively. Table 4 shows that the increase in the content restriction badly hurts the ROW firms and significantly helps the NA firms. Many of the changes in Table 4 are roughly double the changes in Table 2. The rent-shifting effect is particularly evident. On the other hand, see we that total employment in the auto sector is still relatively insensitive to the content rule. Losses in autos and parts production are largely offset by increases in engine production. But it remains the case that the content restriction fails to protect North American employment in the auto sector.

The results in Table 5 are relatively similar to those in Table 3. Again we see that the additional of the VER to the content rule fails to boost the profits of the NA firms relative to the content rule alone. Total auto sector employment is about the same as in NAFTA and $1.5 \%$ higher than with the content restriction alone. In addition to the rent-shifting effect between the two firm types, we do see a small anti-competitive effect insofar as the total industry profits increase (this number is total auto industry profits divided by 
the total initial auto sector capital stocks located in North America). 
Table 4

\% Changes in North American Production and Employment Experiment: Add a $67.5 \%$ NA Content Rule to NAFTA (i.e., NAFTA without the Content Rule is the "Benchmark") Free Entry

$\begin{array}{lccc} & \text { NA Firms } & \text { ROW firms } & \text { TOTAL } \\ \text { Auto Production } & 5.31 & -55.92 & -7.45 \\ \text { Engine Production } & 12.95 & -37.03 & 7.76 \\ \text { Parts Employment } & 3.61 & -43.18 & -1.68 \\ \text { Total NA Employment } & 6.19 & -47.89 & -0.73\end{array}$

Fixed Number of Firms

NA Firms ROW firms TOTAL

Auto Production

3.31

$-47.41$

$-7.35$

Engine Production

8.76

$-27.97$

4.71

Parts Employment

$-2.13$

$-32.01$

$-1.73$

Total NA Employment

3.85

$-37.89$

$-1.53$

Profits*

2.52

$-12.16$

$-0.01$ 
Table 5

\% Changes in North American Production and Employment Experiment: Add a $67.5 \%$ NA Content Rule to NAFTA plus a VER on ROW Auto

Exports to NA in order to hold imports at NAFTA level

Free Entry

$\begin{array}{lccc} & \text { NA Firms } & \text { ROW firms } & \text { TOTAL } \\ \text { Auto Production } & -0.98 & -12.98 & -3.46 \\ \text { Engine Production } & 1.28 & 10.50 & 2.24 \\ \text { Parts Employment } & -0.73 & 17.72 & 1.35 \\ \text { Total NA Employment } & -0.47 & 4.54 & 0.17\end{array}$

Fixed Number of Firms

NA Firms ROW firms TOTAL

$\begin{array}{lrrr}\text { Auto Production } & -1.69 & -8.60 & -3.15 \\ \text { Engine Production } & -0.60 & 11.08 & 0.69 \\ \text { Parts Employment } & -1.32 & 24.50 & 1.60 \\ \text { Total NA Employment } & -1.42 & 9.76 & 0.02 \\ \text { Profits } & 1.08 & -4.29 & 0.17\end{array}$

Profit figures give the change in total (world) firm profits divided by the initial value of auto capital owned by that firm type located in NA. 


\section{Summary and Conclusions}

The purpose of this paper is to examine domestic-content provisions (rules of origin) which must be part of any regional trade agreement. These rules specify the extent to which a product is "domestic" and hence may be freely traded within the block. The more specific goal of the paper is to analyze these restrictions in the setting of an oligopolistic industry, in which the content rules may generate anti-competitive and rent-shifting effects.

Two theoretical sections of the paper, sections 2 and 3 , present simple ways of looking at the problem. Section 2 derives the effects of the content restrictions in terms of intra-firm shadow values for domestic versus imported intermediate inputs. The content restriction is essentially a tax on the imported input and a subsidy on the domestic input. Section 3 presents a simple twofirm mini-model with Cournot competition, in which the content restriction is binding on one firm and not the other. This mini-model illustrates the rent shifting effect in which the content rule shifts profits from the firm on which the rule binds to the firm on which the constraint is slack. A numerical example using this model also illustrates the anti-competitive effect: the possibility that the content rule raises total industry profits. Under Cournot competition, the two firms are producing considerably more than the collusive (joint-profit-maximizing) amount, and the content rule helps to raise the finalgood price by restricting industry output.

In sections four and five, we extend our earlier work (LMR 1994a,b) by explicitly analyzing the content rule in the proposed NAFTA, especially with respect to its effects on the two firm types and on overall North American auto sector output and employment. Results do reveal a significant rentshifting effect in favor of North American firms (which rely less on imported intermediate inputs). The measure is also shown to decrease total North American auto and parts output, and total employment (including parts and engines). In this respect, the content rule can be branded "anti-competitive." 
It clearly fails to protect North American employment.

Some of these results are heavily influenced by the fact that the ROW firms can mitigate the effects of the content rule by switching from North American production to exports to North America from ROW. We thus compute an additional scenario, in which a VER is imposed on the ROW firms such that they cannot export more to North America than the amount they export under NAFTA with no content rule. Table 3 shows that this shifts production from the NA to the ROW firms, but has only a very small effect at increasing total North American auto sector employment relative to the content rule alone. Consistent with the theoretical results of Harris (1985) and Krishna (1989), the VER increases total auto industry profits (but by a tiny amount) and shifts profits from the NA to the ROW firms. ${ }^{8}$

In order to illustrate the sensitivity of the results to the level of the content restriction, we repeat the two experiments in Tables 4 and 5, raising the content rule by $5 \%$ to $67.5 \%$. We see a qualitatively similar pattern of results, but with the effects greatly increased in quantitative terms. Many of the effects double (e.g., the effect on profits), which helps us understand while the level of the content restriction was the subject of intense bargaining in the NAFTA talks. The imposition of the higher content restriction plus the VER leads to a very small but positive increase in total industry profits relative to NAFTA with no content rule, illustrating the possible anti-competitive effect of the two measures combined.

${ }^{8}$ We do not report welfare effects because they are very small. Although NAFTA increases Mexican welfare by $0.3 \%$ (free entry) or $2.1 \%$ (fixed numbers of firms), the addition of the content rule or content rule plus VER have little additional effect (less than $0.1 \%$ ). 


\section{References}

Eaton, Jonathan and Gene M. Grossman (1985), "Optimal Trade and Industrial Policy under Oligopoly, " Quarterly Journal of Economics $101,383-406$.

Harris, Richard (1985), "Why Voluntary Export Restraints are 'Voluntary'," Canadian Journal of Economics 18, 799-809.

Krishna, Kala (1989), "Trade Restrictions as Facilitating Practices," Journal of International Economics 26, 251-270.

Lopez-de-Silanes, Florencio, James R. Markusen, and Thomas F. Rutherford (1994a), "Complementarity and Increasing Returns in Intermediate Inputs," Journal of Development Economics, forthcoming.

Lopez-de-Silanes, Florencio, James R. Markusen, and Thomas F. Rutherford (1994b), "The Auto Industry and the North American Free-Trade Agreement: Employment, Production and Welfare Effects, " in Clint Shields and Joseph Francois (editors), Economy-Wide Modeling of the Economic Implications of a FTA with Mexico and a NAFTA with Canada and Mexico (London: Cambridge University Press), forthcoming.

Markusen, James, Thomas Rutherford, and Linda Hunter (1993), "Trade Liberalization in a Multinational-Dominated Industry, "under revision for the Journal of International Economics.

Data sources and calibration procedures are given in Lopez-deSilanes, Markusen, and Rutherford (1994a,b). These papers are available from the authors, and we will provide the model on disk for those interested. The model may be run with the new version of GAMS which incorporates Rutherford's MPS/GE. Contact Jim Markusen: 303-492-0748, 303-492-8960 (FAX). This version of the paper is very preliminary. Comments and additional references would be greatly appreciated. 